\title{
Perceptual Aberrations Impair Mental Own-Body Transformations
}

\author{
C. Mohr \\ University of Bristol
}

\author{
O. Blanke \\ École Polytechnique Fédérale de Lausanne
}

\author{
P. Brugger \\ University Hospital Zurich
}

\begin{abstract}
Dysfunctional self and bodily processing have been reported from the schizophrenia spectrum. Here, the authors tested 72 students (40 women) to determine whether performance in a mental own-body transformation task relates to self-rated frequency of spontaneously experienced schizotypal body schema alterations (perceptual aberration). Participants provided speeded left-right decisions concerning the body of a visually depicted human figure (front view vs. back view). For men, reaction times to disembodied perspectives increased with increasing scores on a validated perceptual aberration scale. This finding constitutes behavioral evidence for the clinically postulated association between aberrant bodily experiences during everyday life and aberrant processing in a mental own-body transformation task arguably reflecting mild dysfunction at the temporo-parietal junction.
\end{abstract}

Keywords: self-processing, schizophrenia spectrum, gender, individual differences, out-of-body experience

Current concepts of the self have been influenced by a number of academic disciplines including theology, philosophy, and psychology (Churchland, 2002; Gallagher, 2000, 2005; Metzinger, 2003; Neisser, 1988). In a nutshell, what makes us who we are is that we own a body, which we feel and steer and with which we interact with the environment to build up a personal history (Churchland, 2002; Gallagher, 2005; Kircher \& David, 2003; Tsakiris \& Haggard, 2005). Observations from psychiatry and neurology show that the unity of the self is not as obvious as it may appear if judged solely by the experiences of healthy persons (see Blanke, Landis, Spinelli, \& Seeck, 2004; Brugger, Regard, \& Landis, 1997; Churchland, 2002; Farrer et al., 2004; Frith \& Corcoran, 1996; Kircher \& David, 2003, for recent accounts). Along the schizophrenia spectrum, disturbances in self-agency (Farrer et al., 2004; Lindner, Thier, Kircher, Haarmeier, \& Leube,

C. Mohr, Department of Experimental Psychology, University of Bristol, Bristol, United Kingdom; O. Blanke, Laboratory of Cognitive Neuroscience, École Polytechnique Fédérale de Lausanne, Lausanne, Switzerland; P. Brugger, Department of Neurology, Neuropsychology Unit, University Hospital Zurich, Zurich, Switzerland.

This research was supported by the Leenaards Foundation, Sandoz Foundation, Swiss National Science Foundation Grant \#3100-67168.01 and Nuffield Foundation Grant \#SGS/01190/G.

We thank the 2nd year psychology students for their participation during their experimental laboratory classes (Spring 2005). Further thanks to Alex Bright-Paul, Nathalia Gjersoe, Jennifer McBride, Sara Nelson, and Victoria Walker for help in study preparation and data collection. Finally, we are grateful to Flora C. L. Wilson (Bristol) and Angela Rowe (Bristol) for their editorial assistance.

Correspondence concerning this article should be addressed to Christine Mohr, Department of Experimental Psychology, University of Bristol, 12a Priory Road, Bristol BS8 1TU, United Kingdom. E-mail: christine .mohr@bris.ac.uk
2005; Spence et al., 1997), self-other distinction (Gallup, Anderson, \& Platek, 2003; Platek \& Gallup, 2002), theory of mind (Frith \& Corcoran, 1996; Langdon \& Coltheart, 1999), and visualperspective taking (Langdon \& Coltheart, 2001) have been reported. With specific reference to an integrated bodily selfexperience, distorted body perceptions have been discussed as an important feature in both schizophrenia (Angyal, 1936; Bleuler, 1950; Chapman, Chapman, \& Raulin, 1978) and healthy schizotypy (Lenzenweger, 2000; Meehl, 1990; Rado, 1960). Moreover, high as compared with low schizotypal individuals have been found to be more susceptible to experimental distortions of corporeal awareness (Burrack \& Brugger, 2005).

Studies targeting disturbed feelings of self-processing in schizophrenia have highlighted the importance of the cortex at the junction of the temporal and parietal lobes (temporo-parietal junction or TPJ; Farrer et al., 2004; Spence et al., 1997). In a PET study, Spence et al. (1997) asked patients with passivity symptoms (loss of agency, alien control) to move a joystick with the right hand to the sound of auditory stimuli. When compared with healthy controls as well as to patients without passivity symptoms, this patient population revealed a hyperactivation of the right TPJ and the cingulate gyrus during hand movements. In another PET study, Farrer et al. (2004) tested action attribution in patients with Schneiderian first-rank symptoms (e.g., auditory hallucinations, thought intrusions, delusions). Participants made self-other decisions about seen hand movements on a screen. The spatial match between one's own hand position and the one seen on the screen was gradually distorted. Supporting previous reports that the right TPJ is involved in the attribution of action to another agent (e.g., Ruby \& Decety, 2001), healthy participants' brain activation at this locus increased with increasing deviance of seen and felt hand positions. In first-rank patients, this relationship was absent or much weaker and was associated with patients' first-rank symp- 
toms. The authors also reported that these patients' lack of increase in activation with increasing distortion was associated with an abnormally high level of activation in the perfectly matching condition. Thus, the patients showed high activity in the right angular gyrus when they experienced being the agent of their actions, whereas this activation in healthy controls is only seen when agency is allocated to another person. The role of this brain region in self and bodily processing is further supported by functional imaging studies in healthy individuals (Astafiev, Stanley, Shulman, \& Corbetta, 2004; Bonda, Petrides, Frey, \& Evans, 1995; Calvert, Campbell, \& Brammer, 2000; Lobel, Kleine, Bihan, Leroy-Willig, \& Berthoz, 1998; Uddin, Kaplan, Molnar-Szakacs, Zaidel, \& Iacoboni, 2005) and by patients with focal brain lesions (e.g., Apperly, Samson, Chiavarino, \& Humphreys, 2004; Scepkowski \& Cronin-Golomb, 2003; Semenza, 1988).

Of specific interest to the present study are individuals who have had an out-of-body experience (OBE), a striking distortion in the experienced spatial unity of self and body. These individuals experience the transient, but highly veridical, impression that their self is located outside of their physical body boundaries and that both the world and the physical body is seen from this elevated spatial position (Blanke \& Mohr, 2005, for a recent overview). In line with the role of the TPJ in self- and own-body processing, respectively, this brain site has been associated with OBEs of neurological origin (Blanke et al., 2004, 2005; Blanke \& Mohr, 2005; Blanke, Ortigue, Landis, \& Seeck, 2002). Given that selfprocessing deficits along the schizophrenia spectrum and the generation of OBE have been associated with the same brain site, some authors have suggested that these phenomena underlie a common cerebral denominator (Mohr \& Blanke, 2005; Uddin et al., 2005). Phenomenologically, such a suggestion would also be supported by findings from McCreery and Claridge (1995, 2002), who observed that OBE individuals have higher positive schizotypy scores than individuals who have never experienced an OBE. Unfortunately, OBEs are rare and occur spontaneously in the healthy as well as clinical populations, making their experimental investigation difficult. However, it has been suggested that brain processes during the mental transformation of one's own body might engage similar brain mechanisms as those activated during OBEs (Amorim, 2003; Blackmore, 1982; Brugger, 2002; Cook \& Irwin, 1983). Findings from an event-related potential (ERP) study and a transcranial magnetic stimulation (TMS) study testing independent healthy participants as well as a patient with epilepsy confirmed that the TPJ is predominantly implicated in both the mental transformation of one's own body and OBEs (Blanke et al., 2005). In more detail, the ERP study showed the selective activation of the TPJ at 330-400 ms after stimulus onset when healthy volunteers imagined themselves in the position and visual perspective that is generally reported by people experiencing spontaneous OBEs. The TMS study showed that interference with the TPJ by TMS at this time impaired mental transformation of the own body in healthy volunteers relative to TMS over a control site at the intraparietal sulcus. No such inference was observed for imagined spatial transformations of external objects suggesting the selective implication of the TPJ in mental imagery of one's own body. Finally, in an epileptic patient with OBEs originating from the TPJ, it was shown that partial activation of the seizure focus during mental transformations of her body and visual perspective mimicking her OBE percept. These results suggested that the TPJ is a crucial structure for the conscious experience of the normal selfmediating spatial unity of self and body.

The present study set out to investigate whether schizotypal individuals, in particular those showing aberrant bodily experiences during their everyday lives, might show impaired performance in mental own-body transformations as compared with nonschizotypal individuals (see Mohr \& Blanke, 2005, for further details on generation of this study question). More specifically, healthy right-handed participants completed the 35-item selfreport perceptual aberration (PA) scale by Chapman et al. (1978) and performed the same mental own-body transformation task as used before (Blanke et al., 2005). In this task, individuals are asked to imagine themselves in the position of the schematic human figure and to report whether the salient right or left hand in the picture corresponds to their actual right or left hand (see Figure 1). The use of the PA scale seems particularly appropriate for three reasons. First, PA taps most closely on bodily aberrations compared with other schizotypal dimensions. Second, individuals high in PA might have an enhanced risk of developing psychosis (Chapman, Chapman, Kwapil, Eckblad, \& Zinser, 1994). Third, such individuals were found to show similar neuropsychological deficits as described in patients with schizophrenia (e.g., Lenzenweger, 1994; Park, 1999; Tallent \& Gooding, 1999). Here, we predicted that the ability to adopt an imagined, disembodied perspective, that is, to perform a mental own-body transformation in space, would be hampered as a function of increasing scores on the PA scale. Such a finding would support the assumption of a common cerebral denominator in both body aberrations along the schizophrenia spectrum and OBEs (Mohr \& Blanke, 2005).

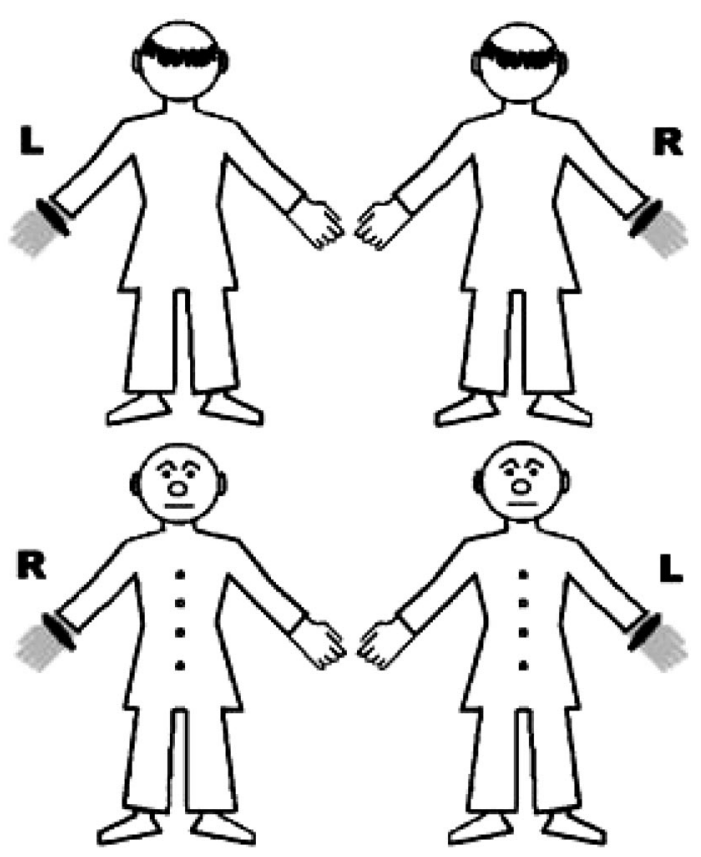

Figure 1. Stimuli used in the mental own-body transformation task. A gray glove and a black ring always mark one hand. The correct responses are indicated with letters $(\mathrm{L}=$ left; $\mathrm{R}=$ right). 


\section{Method}

\section{Participants}

Seventy-nine healthy volunteers (43 women) with a mean age of 20.5 years $(S D= \pm 2.7$ years, range $=18-37$ years $)$ took part in the study. Half of the participants were undergraduate students receiving course credit for their participation, whereas the remaining participants were undergraduate students from various faculties. The affiliation of the latter participants remained anonymous, as each undergraduate student of the local Psychology Department was asked only to recruit an additional undergraduate student of the opposite sex to balance gender differences $(70 \%$ of the psychology students were women). Prior to the experiment, which was approved by the local Ethical Committee of the University of Bristol, all participants provided written, informed consent. Testing took place at several sessions in a classroom setting.

\section{Stimuli and Procedure}

Stimuli. We used stimuli modified from those used in previous studies testing mental own-body transformations (Blanke et al., 2005; Parsons, 1987; Zacks, Rypma, Gabrieli, Tversky, \& Glover, 1999). The schematic human figure faced either toward or away from the volunteer. Front- and back-facing figures had the same outline and differed only in the rendering of the clothing of the figure and the presence of a face (front facing) or the back of a head (back facing, Figure 1). The figure's hands were marked such that one hand was perceptually salient and appeared as wearing a gray glove and a black ring at the wrist. The salient hand could appear on either the right or left hand (see Figure 1).

Procedure. Participants were asked to perform right-left judgments about the schematic figures after having imagined themselves to be in the figure's body position and to have the respective visuospatial perspective (see Figure 1). By button press on a keyboard, participants had to indicate whether the salient hand of the figure (see below) would be the right or left hand given that they were in the figure's position. Stimuli were presented in the center of the computer screen $\left(5.0^{\circ} \times 6.1^{\circ}\right.$ of visual angle $)$ until a response was provided. The interstimulus interval was $1,000 \mathrm{~ms}$. Participants were instructed to respond as quickly and precisely as possible, but to always perform the mental transformation of their body prior to giving their response. The experimenters instructed half of the participants to use the right hand for responding and instructed the remaining participants to use the left hand for responding. Left judgments were indicated by button presses of the index finger, and right judgments were indicated by button presses of the middle finger. The experimental block included a total of 120 trials, which consisted of 30 presentations of each stimulus in a randomized order. We calculated mean reaction times for correct responses. Response latencies faster than $200 \mathrm{~ms}$ and slower than 5,000 ms were discarded from further analysis (see Harris, Harris, \& Caine, 2002).

\section{Questionnaires}

After the experiment, participants completed a standardized handedness questionnaire (Oldfield, 1971) and the 35-item true-false self-report PA Scale (Chapman et al., 1978). Typical items of this latter scale are "Occasionally I have felt as though my body did not exist" (keyed true) and "I have never felt that my arms or legs have momentarily grown in size" (keyed false). Additional literature concerning reliable and valid use of the PA scale in the study of schizotypy can be found elsewhere (e.g., Chapman et al., 1994; Lenzenweger, 1994; Park, 1999; Tallent \& Gooding, 1999). Individuals were also asked about their previous neurological or psychiatric history. Additionally, we asked participants whether they had consumed any psychoactive substances within the previous 2 months. It was clear to volunteers that participation was anonymous, as the only personal information they provided on the questionnaires was their gender and age. Apart from this information, the questionnaires and the behavioral results were coded by numerical values devoid of any personal information about the participant.

\section{Data Analysis}

Seven participants were excluded because of non-right-handedness $(n=$ 3; 2 men), psychoactive substance use within the previous 2 months according to self-report ( $n=3 ; 2$ women), or a low number of correct responses in the computer task ( $n=3 ; 2$ women). The 3 participants with low accuracy were clear outliers; they had on average $( \pm S D) 8( \pm 7.9)$ correct responses for the back-facing and $8( \pm 8.9)$ correct responses for front-facing figures, whereas those with high accuracy had on average 57.1 $( \pm 4.2)$ correct responses for back-facing and $56.9( \pm 4.4)$ correct responses for front-facing figures. Note that one of the excluded women was non-right-handed and had a low number of correct responses, and a second woman had a previous drug history and a low number of correct responses. Thus, the analyses reported below are based on a sample of 72 participants $(n=40$ women $)$.

To test for a general influence of gender on task performance, we conducted two separate repeated measures analyses of variance (ANOVAs), with the body stimuli (back facing vs. front facing) as the repeated measures factor and gender (men vs. women) as a between subjects factor, on the number of correct responses and the reaction times for correct responses. Moreover, we used Pearson correlation analyses to correlate the number of correct responses and the respective reaction times for front-facing and back-facing figures with individuals' PA scores for the whole sample as well as for the two gender groups separately. Kolmogorov-Smirnov statistics confirmed that all variables (PA scores, response latencies for front- and back-facing figures, respectively) were normally distributed (all $d \mathrm{~s}<.16$, all $p \mathrm{~s}>.05$ ). All $p$ values are two-tailed, and the significance level was set to $\alpha=.05$.

\section{Results}

\section{Participants}

The mean $( \pm S D)$ age (in years) did not differ between women $(20.4 \pm 2.8)$ and men $(20.6 \pm 3.9), t(70)=.31, p=.76$. In line with previous reports (Brugger \& Graves, 1997; Chapman, Edell, \& Chapman, 1980; Jaspers-Fayer \& Peters, 2005; Weinstein \& Graves, 2001; but see Meyer \& Hautzinger, 1999), positive schizotypy scores were higher in female $(6.4 \pm 5.1)$ as compared with male participants $(4.0 \pm 4.6), t(70)=2.11, p=.04$.

\section{Mental Own-Body Transformation Task}

The ANOVA on reaction times for correct decisions replicated previous findings (Blanke et al., 2005; Zacks et al., 1999), that is, response latencies were longer for front-facing $(950.0 \pm 257.5)$ than back-facing $(782.0 \pm 158.8)$ figures, $F(1,70)=123.48, p<$ .0001 . Neither the main effect for gender, $F(1,70)=0.69, p=$ .41 , nor the interaction between gender and position, $F(1,70)=$ $0.29, p=.59$, were significant. The ANOVA on the number of correct responses was not significant for gender, $F(1,70)=0.00$, $p=.99$, body position, $F(1,70)=0.18, p=.67$, or the interaction between gender and body position, $F(1,70)=2.14, p=.15$.

\section{Relationship Between PA Scores and Task Performance}

For the whole sample, increasing PA scores correlated with increasing reaction times for front-facing figures $(r=.26, p=.03)$ and back-facing figures $(r=.26, p=.03)$. The same analyses for the gender groups separately indicated that these significant cor- 
relations reflected male (front facing: $r=.39, p=.03$; back facing: $r=.41, p=.02$ ), but not female performance (front facing: $r=.22, p=.18$; back facing: $r=.18, p=.27$; see Figure 2).

For the whole sample, the number of correct responses in both the front-facing $(r=.13, p=.27)$ and back-facing $(r=-.00, p=$ .99) position was unrelated to PA scores. The same was true for the female participants (back facing $r=.17, p=.30$, front facing $r=$ $.15, p=.34$ ) and male participants (back facing $r=.10, p=.58$; front facing $r=-.22, p=.23$ ) separately.

\section{Discussion}

The present study investigated the idea that positive schizotypal individuals, in particular those endorsing perceptual aberrations, might be impaired in the performance of mental own-body transformations (Mohr \& Blanke, 2005). This suggestion was based on several previous research findings. First, self-processing (including the experience of a unified self and body) has been found to be impaired along the schizophrenia spectrum (e.g., Farrer et al., 2004; Frith \& Corcoran, 1996; Gallup et al., 2003; Langdon \& Coltheart, 1999, 2001; Lindner et al., 2005; Platek \& Gallup, 2002; Spence et al., 1997). Second, high as compared with low schizotypal individuals were found to be more susceptible to distortions of body schema (Burrack \& Brugger, 2005) and to be specifically impaired in egocentric visuospatial perspective taking (Langdon \& Coltheart, 2001). The findings of the present study confirmed this proposition, but only for our healthy right-handed male participants.

In the mental own-body transformation task, individuals were required to take the position of a presented schematic human figure and to decide whether the salient right or left hand would be their own right or left hand after having imagined that they were in the position of the figure (see Figure 1). Across participants, we replicated previous observations of longer reaction times to frontfacing as compared with back-facing figures (Blanke et al., 2005; Parsons, 1987; Ratcliff, 1979; Zacks et al., 1999). This overall finding is well in agreement with previous observations regarding mental rotation of objects (Shepard \& Metzler, 1971; Wohlschläger \& Wohlschläger, 1998) and body parts (Bonda et al., 1995; Cooper \& Shepard, 1975; Petit, Pegna, Mayer, \& Hauert, 2003): reaction times are longer when the position of a stimulus (the own-body position in the present case) does not match that of the target stimulus (front-facing figures in the present case). Across participants, we also found that response latencies for right-left decisions for both front-facing and back-facing figures increased with increasing PA scores (see Figure 2). The comparable observation for front-facing and back-facing figures supports previous observations that spatial mental own-body transformations are not only performed for the more cognitively demanding front-facing figures but also for the back-facing figures, which spatially match the own actual body position (Blanke et al., 2005; Zacks et al., 1999).

We chose the present mental own-body transformation task for two reasons. First, previous research has found that this task taps into brain processes implicated in the generation of an aberrant self-experience, that is, OBEs (Blanke et al., 2005). Second, a common brain denominator can be suggested phenomenologically and anatomically for individuals with OBEs and along the schizo-
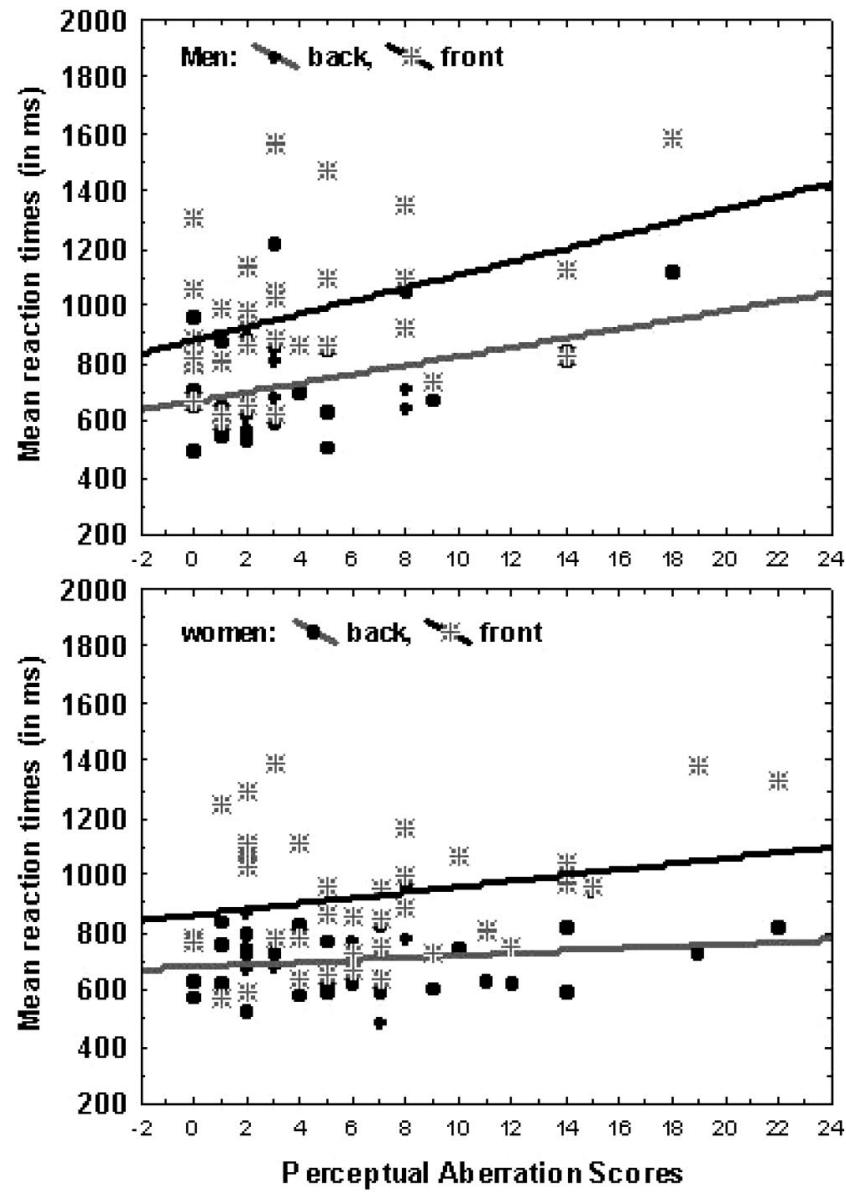

Figure 2. Reaction times (in ms) for back-facing (black dots) and frontfacing (gray crosses) schematic human figures as a function of individuals' perceptual aberration scores for men (top panel) and women (bottom panel) separately.

phrenia spectrum, respectively. For instance, positive schizotypy (McCreery \& Claridge, 1995) and paranormal belief (Tobacyk \& Mitchell, 1987) have previously been shown to be higher in individuals reporting OBEs. Impaired self-processing in both individuals along the schizophrenia spectrum and those with OBEs has been related to a dysfunctional integration of information at the TPJ (e.g., Blanke et al., 2004; Blanke \& Mohr, 2005; Farrer et al. 2004; Spence et al., 1997). This latter observation would be in line with independent research testing healthy participants showing that the TPJ is important in mental transformation of body parts (Bonda et al., 1995) as well as in the mental transformation of the entire body (Blanke et al., 2005; Ratcliff, 1979; Zacks et al., 1999). Consequently, we conjecture that the relatively slower reaction times in the present task with increasing PA scores might reflect relatively impaired integration of bodily information in brain areas around the TPJ. We also conjecture such a relationship for a healthy population, free of neuroleptic medication or illnessrelated side effects (e.g., duration of illness, medication). Thus, a link between PAs and the TPJ could be suggested for healthy individuals and seems to be independent of acute psychotic illness. The processing of information with respect to the body and self has 
been linked to several other brain areas mediating different isolated aspects of the self, including prefrontal cortex, anterior cingulate, postcentral gyrus, precuneus, occipito-temporal junction, insula, and superior parietal lobule (e.g., Blanke et al., 2004; Decety \& Sommerville, 2003; Jeannerod, 2001; Ruby \& Decety, 2001; Vogeley \& Fink, 2003). It is thus likely that the here observed correlations might also extend to other brain regions.

The specificity of these findings in our male participants needs further explanation. As a first speculation, the sex difference might have emerged because of a different hemispheric specialization in men and women. Impairments in schizophrenia have been found to be more pronounced in male than female patients (Hafner, 2003; Kumari, Aasen, \& Sharma, 2004), in particular when hemispheric laterality is considered (Falkai et al., 1992; Ragland, Gur, Klimas, McGrady, \& Gur, 1999). The same holds true for hemispheric functions in healthy individuals in general (McGlone, 1980; Meinschaefer, Hausmann, \& Güntürkün, 1999) and healthy schizotypal individuals in particular (Mohr, Röhrenbach, Laska, \& Brugger, 2001). We asked participants to imagine their body and perspective in the position of another person's body in space, requiring own-body imagery and spatial perspective taking. The spatial perspective component of our task (taking another perspective) might rely more on the right as compared with the left hemisphere (Chaminade, Meltzoff, \& Decety, 2005; Harris et al., 2002; Ruby $\&$ Decety, 2001). In addition, both the own-body transformation task used in the present study (Blanke et al., 2005) and the occurrence of OBEs (Blanke \& Mohr, 2005) appear to rely more on the right than left hemisphere. It could be conjectured that a relatively more asymmetrical hemispheric functioning in men and a more symmetrical hemispheric functioning in women might have rendered performance of women less dependent on an integrative functioning of the right hemisphere.

Another explanation would focus on sex differences in mental perspective taking. Men have frequently been reported to be superior to women in spatial functions, in particular when mental rotations are considered (Seurinck, Vingerhoets, de Lange, \& Achten, 2004, for recent overview). However, this sex difference has been found to depend on variables such as gender role belief (Massa, Mayer, \& Bohon, 2005), time constraints (Peters, 2005), guessing tendencies (Voyer \& Saunders, 2004), and stimulus complexity (Parsons et al., 2004). Moreover, different spatial transformation abilities and strategies have been dissociated (e.g., Hegarty \& Waller, 2004; Kosslyn, DiGirolamo, Thompson, \& Alpert, 1998; Tomasino \& Rumiati, 2004; Wraga, Shephard, Church, Inati, \& Kosslyn, 2005; Zacks et al., 1999; Zacks, Vettel, \& Michelon, 2003). It might have been the case that women and men applied different strategies to take another egocentric perspective in space. Massa et al. (2005) tested gender role beliefs in women performing embedded figures tests. The authors found that women with a more masculine gender role performed better when they were told the task measured spatial ability, whereas women with a more feminine gender role performed better when they were told the task measured empathy. Empathy is thought to reflect another form of perspective taking (Davis et al., 2004; Vogeley \& Fink, 2003) and has been found to be higher in women than men (Baron-Cohen \& Wheelwright, 2004). It might have been the case that women used more social than spatial perspective-taking abilities, whereas men used more spatial than social perspective abilities, and this might have led to the observed behavioral differ- ences. Such a sex difference in task strategies might also explain the male advantage when performing right-left decisions in general and on human bodies in particular (Harris \& Gitterman, 1978; Ofte, 2002; Ofte \& Hugdahl, 2002). We here acknowledge that both explanations regarding the present sex difference are plausible and that the issue will have to be settled in further experimental studies.

As a final note, we would like to mention two experimental elements of the present study, which should be taken into account when performing follow-up investigations. First, the study would have profited from taking response hand into consideration. Selfinformation has been found to result in faster responding with the left than right hand in healthy participants (Keenan et al., 1999; Platek \& Gallup, 2002; Platek, Myers, Critton, \& Gallup, 2003), pointing to a right hemisphere advantage for self-information. High schizotypal individuals, however, did not reveal this lefthand advantage (Platek \& Gallup, 2002; Platek et al., 2003). For the present study, these findings would imply that the relationship between PA scores and reaction times in the mental own-body transformation might be a function of response hand. Accounting for this variable would help to disentangle hemispheric contributions in the present findings, including the one on sex differences. Second, the present study only accounted for one aspect of schizotypy. However, along the schizophrenia spectrum (including healthy schizotypy) at least three symptom groups have been dissociated (Venables \& Rector, 2000, for overview). Future studies should thus investigate whether the observed relationship between task performance and schizotypal features is specific to perceptual aberration (positive schizotypy) or to schizotypy in general (including negative schizotypy and cognitive disorganization).

In conclusion, we showed that PA in healthy male participants relates to delayed performance in a mental own-body transformation task. Given the previous evidence that this task taps on multisensory integrative functioning of the TPJ (Blanke et al., 2005), the present findings would support the idea that positive schizotypal features might be associated with a disintegration of multisensory bodily information at this brain site (Mohr \& Blanke, 2005). It is suggested that mental own-body transformations are a quickly and easily performed indirect measure to investigate such complex brain processes as the integration of the self into a unitary bodily reference frame.

\section{References}

Amorim, M.-A. (2003). "What is my avatar seeing?": The coordination of "out-of-body" and "embodied" perspectives for scene recognition across views. Visual Cognition, 10, 157-199.

Angyal, A. (1936). The experience of the body-self in schizophrenia. Archives of Neurology \& Psychiatry, 35, 1029-1053.

Apperly, I. A., Samson, D., Chiavarino, C., \& Humphreys, G. W. (2004) Frontal and temporo-parietal lobe contributions to theory of mind: Neuropsychological evidence from a false-belief task with reduced language and executive demands. Journal of Cognitive Neuroscience, 16, 1773-1784.

Astafiev, S. V., Stanley, C. M., Shulman, G. L., \& Corbetta, M. (2004) Extrastriate body area in human occipital cortex responds to the performance of motor actions. Nature Neuroscience, 7, 542-548.

Baron-Cohen, S., \& Wheelwright, S. (2004). The empathy quotient: An investigation of adults with Asperger syndrome or high functioning autism, and normal sex differences. Journal of Autism and Developmental Disorders, 34, 163-175. 
Blackmore, S. J. (1982). Beyond the body. An investigation of out-of-body experiences. London: Heinemann.

Blanke, O., Landis, T., Spinelli, L., \& Seeck, M. (2004). Out-of-body experience and autoscopy of neurological origin. Brain, 127, 243-258.

Blanke, O., \& Mohr, C. (2005). Out-of-body experience, heautoscopy, and autoscopic hallucination of neurological origin. Implications for neurocognitive mechanisms of corporeal awareness and self consciousness. Brain Research Reviews, 50, 184-199.

Blanke, O., Mohr, C., Michel, C. M., Pascual-Leone, A., Brugger, P., Landis, T., et al. (2005). Linking out-of-body experience and self processing to mental own-body image at the temporo-parietal junction. Journal of Neuroscience, 25, 550-557.

Blanke, O., Ortigue, S., Landis, T., \& Seeck, M. (2002, September 19). Stimulating illusory own-body perceptions. Nature, 419, 269-270.

Bleuler, E. (1950). Dementia Praecox or the group of the schizophrenias. New York: International University Press. (Original work published 1911).

Bonda, E., Petrides, M., Frey, S., \& Evans, A. (1995). Neural correlates of mental transformations of the body-in-space. Proceedings of the National Academy of Sciences, USA, 92, 11180-11184.

Brugger, P. (2002). Reflective mirrors: Perspective taking in autoscopic phenomena. Cognitive Neuropsychiatry, 7, 179-194.

Brugger, P., \& Graves, R. E. (1997). Testing vs. believing hypotheses: Magical ideation in the judgment of contingencies. Cognitive Neuropsychiatry, 2, 251-272.

Brugger, P., Regard, M., \& Landis, T. (1997). Illusory reduplication of one's own body: Phenomenology and classification of autoscopic phenomena. Cognitive Neuropsychiatry, 2, 19-38.

Burrack, A., \& Brugger, P. (2005). Individual differences in susceptibility to experimentally induced phantom sensations. Body Image, 2, 307-313.

Calvert, G. A., Campbell, R., \& Brammer, M. J. (2000). Evidence from functional magnetic resonance imaging of crossmodal binding in the human heteromodal cortex. Current Biology, 10, 649-657.

Chaminade, T., Meltzoff, A. N., \& Decety, J. (2005). An fMRI study of imitation: Action representation and body schema. Neuropsychologia, $43,115-127$.

Chapman, L. J., Chapman, J. P., Kwapil, T. R., Eckblad, M., \& Zinser, M. C. (1994). Putatively psychosis-prone subjects 10 years later. Journal of Abnormal Psychology, 103, 171-183.

Chapman, L. J., Chapman, J. P., \& Raulin, M. L. (1978). Body-image aberration in Schizophrenia. Journal of Abnormal Psychology, 87, 399407

Chapman, L. J., Edell, W. S., \& Chapman, J. P. (1980). Physical anhedonia, perceptual aberration, and psychosis proneness. Schizophrenia Bulletin, 6, 639-653.

Churchland, P. S. (2002, April 12). Self-representation in nervous systems. Science, 296, 308-310.

Cook, A. M., \& Irwin, H. J. (1983). Visuospatial skills and the out-of-body experience. Journal of Parapsychology, 47, 23-35.

Cooper, L. A., \& Shepard, R. N. (1975). Mental transformations in the identification of left and right hands. Journal of Experimental Psychology: Human Perception and Performance, 104, 48-56.

Davis, M. H., Sonderlund, T., Cole, J., Gadol, E., Kute, M., Myers, M., \& Weihing, J. (2004). Cognitions associated with attempts to empathize: How do we imagine the perspective of others? Personality and Social Psychology Bulletin, 30, 1625-1635.

Decety, J., \& Sommerville, J. A. (2003). Shared representations between self and other: A social cognitive neuroscience view. Trends in Cognitive Sciences, 7, 527-533.

Falkai, P., Bogerts, B., Greve, B., Pfeiffer, U., Machus, B., Folsch-Reetz, B., et al. (1992). Loss of Sylvian fissure asymmetry in schizophrenia. A quantitative post mortem study. Schizophrenia Research, 7, 23-32.
Farrer, C., Franck, N., Frith, C. D., Decety, J., Georgieff, N., d'Amato, T., \& Jeannerod, M. (2004). Neural correlates of action attribution in schizophrenia. Psychiatry Research, 131, 31-44.

Frith, C. D., \& Corcoran, R. (1996). Exploring "theory of mind" in people with schizophrenia. Psychological Medicine, 26, 521-530.

Gallagher, S. (2000). Philosophical conceptions of the self: Implications for cognitive science. Trends in Cognitive Sciences, 4, 14-21.

Gallagher, S. (2005). Metzinger's Matrix: Living the virtual life with a real body. Psyche, 11, 1-9.

Gallup, G. G., Jr., Anderson, J. R., \& Platek, S. M. (2003). Self-awareness, social intelligence, and schizophrenia. In S. David, \& T. Kircher (Eds.), The Self and schizophrenia: A neuropsychological perspective. Cambridge, United Kingdom: Cambridge University Press.

Hafner, H. (2003). Sex differences in schizophrenia. Psychoneuroendocrinology, 28 (Suppl. 2), 17-54.

Harris, I. M., Harris, J. A., \& Caine, D. (2002). Mental-rotation deficits following damage to the right basal ganglia. Neuropsychology, 16, $524-537$.

Harris, L. J., \& Gitterman, S. R. (1978). University professors' selfdescriptions of left-right confusability: Sex and handedness differences. Perceptual and Motor Skills, 47, 819-823.

Hegarty, M., \& Waller, D. (2004). A dissociation between mental rotation and perspective-taking spatial abilities. Intelligence, 32, 175-191.

Jaspers-Fayer, J., \& Peters, M. (2005). Hand preference, magical thinking and left-right confusion. Laterality, 10, 183-191.

Jeannerod, M. (2001). Neural simulation of action: A unifying mechanism for motor cognition. Neurolmage, 14, S103-S109.

Keenan, J. P., McCutcheon, B., Freund, S., Gallup Jr., G. G., Sanders, G., \& Pascual-Leone, A. (1999). Left hand advantage in a self-face recognition task. Neuropsychologia, 37, 1421-1425.

Kircher, T., \& David, A., (2003). The Self in neuroscience and psychiatry. Cambridge, United Kingdom: Cambridge University Press.

Kosslyn, S. M., DiGirolamo, G. J., Thompson, W. L., \& Alpert, N. M. (1998). Mental rotation of objects versus hands: Neural mechanisms revealed by positron emission tomography. Psychophysiology, 35, 151161.

Kumari, V., Aasen, I., \& Sharma, T. (2004). Sex differences in prepulse inhibition deficits in chronic schizophrenia. Schizophrenia Research, 69, 219-235.

Langdon, R., \& Coltheart, M. (1999). Mentalizing, schizotypy, and schizophrenia. Cognition, 71, 43-71.

Langdon, R., \& Coltheart, M. (2001). Visual perspective-taking and schizotypy: Evidence for a simulation-based account of mentalizing in normal adults. Cognition, 82, 1-26.

Lenzenweger, M. F. (1994). Psychometric high-risk paradigm, perceptual aberrations, and schizotypy: An update. Schizophrenia Bulletin, 20, 121-135.

Lenzenweger, M. F. (2000). Two-point discrimination thresholds and schizotypy: Illuminating a somatosensory dysfunction. Schizophrenia Research, 42, 111-124.

Lindner, A., Thier, P., Kircher, T. T., Haarmeier, T., \& Leube, D. T. (2005). Disorders of agency in schizophrenia correlate with an inability to compensate for the sensory consequences of actions. Current Biology, $15,1119-1124$.

Lobel, E., Kleine, J. F., Bihan, D. L., Leroy-Willig, A., \& Berthoz, A. (1998). Functional MRI of galvanic vestibular stimulation. Journal of Neurophysiology, 80, 2699-2709.

Massa, L. J., Mayer, R. E., \& Bohon, L. M. (2005). Individual differences in gender role beliefs influence spatial ability test performance. Learning and Individual Differences, 15, 99-111.

McCreery, C., \& Claridge, G. (1995). Out-of-the body experiences and personality. Journal of the Society for Psychical Research, 60, 129-148. 
McCreery, C., \& Claridge, G. (2002). Healthy schizotypy: The case of out-of-the-body experiences. Personality and Individual Differences, 32, $141-154$.

McGlone, J. (1980). Sex differences in human brain asymmetry: A critical survey. Behavioral Brain Sciences, 3, 215-263.

Meehl, P. E. (1990). Toward an integrated theory of schizotaxia, schizotypy, and schizophrenia. Journal of Personality Disorders, 4, 1-99.

Meinschaefer, J., Hausmann, M., \& Güntürkün, O. (1999). Laterality effects in the processing of syllable structure. Brain \& Language, 70 , 287-293.

Metzinger, T. (2003). Being no one. Cambridge, MA: MIT Press.

Meyer, T. D., \& Hautzinger, M. (1999). Two-year stability of Psychosis Proneness Scales and their relations to personality disorder traits. Journal of Personality Assessment, 73, 472-488.

Mohr, C., \& Blanke, O. (2005). The demystification of autoscopic phenomena: Experimental propositions. Current Psychiatry Reports, 7, 189-195.

Mohr, C., Röhrenbach, C., Laska, M., \& Brugger, P. (2001). Unilateral olfactory perception and magical ideation. Schizophrenia Research, 47, 255-264.

Neisser, U. (1988). The five kinds of self-knowledge. Philosophical Psychology, 1, 35-59.

Ofte, S. H. (2002). Right-left discrimination: Effects of handedness and educational background. Scandinavian Journal of Psychology, 43, 213219

Ofte, S. H., \& Hugdahl, K. (2002). Right-left discrimination in male and female, young and old subjects. Journal of Clinical and Experimental Neuropsychology, 24, 82-92.

Oldfield, R. C. (1971). The assessment and analysis of handedness: The Edinburgh inventory. Neuropsychologia, 9, 97-113.

Park, S. (1999). Hemispheric asymmetry of spatial working memory deficit in schizophrenia. International Journal of Psychophysiology, 34, 313322.

Parsons, L. M. (1987). Imagined spatial transformation of one's body. Journal of Experimental Psychology: General, 116, 172-191.

Parsons, T. D., Larson, P., Kratz, K., Thiebaux, M., Bluestein, B., Buckwalter, J. G., \& Rizzo, A. A. (2004). Sex differences in mental rotation and spatial rotation in a virtual environment, Neuropsychologia, 42, 555-562.

Peters, M. (2005). Sex differences and the factor of time in solving Vanderberg and Kuse mental rotation problems. Brain and Cognition, 57, 176-184.

Petit, L. S., Pegna, A. J., Mayer, E., \& Hauert, C. A. (2003). Representation of anatomical constraints in motor imagery: Mental rotation of a body segment. Brain and Cognition, 51, 95-101.

Platek, S. M., \& Gallup, G. G., Jr. (2002). Self-face recognition is affected by schizotypal personality traits. Schizophrenia Research, 57, 311-315.

Platek, S. M., Myers, T. E., Critton, S. R., \& Gallup, G. G., Jr. (2003). A left-hand advantage for self-descriptions: The impact of schizotypal personality traits. Schizophrenia Research, 65, 147-151.

Rado, S. (1960). Theory and therapy: The theory of schizotypal organization and its application to the treatment of decompensated schizotypal behavior. In S. C. Scher, \& H. R. Davis (Eds.), The outpatient treatment of schizophrenia (pp. 87-101). New York: Grune and Stratton.

Ragland, J. D., Gur, R. E., Klimas, B. C., McGrady, N., \& Gur, R. C. (1999). Neuropsychological laterality indices of schizophrenia: Interactions with gender. Schizophrenia Bulletin, 25, 79-89.

Ratcliff, G. (1979). Spatial thought, mental rotation and the right cerebral hemisphere. Neuropsychologia, 17, 49-54.
Ruby, P., \& Decety, J. (2001). Effect of subjective perspective taking during simulation of action: PET investigation of agency. Nature Neuroscience, 4, 546-550.

Scepkowski, L. A., \& Cronin-Golomb, A. (2003). The alien hand: Cases, categorizations, and anatomical correlates. Behavioral \& Cognitive Neuroscience Reviews, 2, 261-277.

Semenza, C. (1988). Impairment in localization of body parts following brain damage. Cortex, 24, 443-449.

Seurinck, R., Vingerhoets, G., de Lange, F. P., \& Achten, E. (2004). Does egocentric mental rotation elicit sex differences? NeuroImage, 23, $1440-1449$.

Shepard, R. N., \& Metzler, J. (1971, February 19). Mental rotation of three-dimensional objects. Science, 171, 701-703.

Spence, S. A., Brooks, D. J., Hirsch, S. R., Liddle, P. F., Meehan, J., \& Grasby, P. M. (1997). A PET study of voluntary movement in schizophrenic patients experiencing passivity phenomena (delusions of alien control). Brain, 120, 1997-2011.

Tallent, K. A., \& Gooding, D. C. (1999). Working memory and Wisconsin Card Sorting Test performance in schizotypic individuals: A replication and extension. Psychiatry Research, 89, 161-170.

Tobacyk, J. J., \& Mitchell, T. P. (1987). The out-of-body experience and personality adjustment. The Journal of Nervous and Mental Disease, $175,367-370$

Tomasino, B., \& Rumiati, R. I. (2004). Effects of strategies on mental rotation and hemispheric lateralization: Neuropsychological evidence. Journal of Cognitive Neuroscience, 16, 878-888.

Tsakiris, M., \& Haggard, P. (2005). Experimenting with the acting self. Cognitive Neuropsychology, 22, 387-407.

Uddin, L. Q., Kaplan, J. T., Molnar-Szakacs, I., Zaidel, E., \& Iacoboni, M. (2005). Self-face recognition activates a frontoparietal "mirror" network in the right hemisphere: An event-related fMRI study. NeuroImage, 25, 926-935.

Venables, P. H., \& Rector, N. A. (2000). The content and structure of schizotypy: A study using confirmatory factor analysis. Schizophrenia Bulletin, 26, 587-602.

Vogeley, K, \& Fink, G. R. (2003). Neural correlates of the first-personperspective. Trends in Cognitive Sciences, 7, 38-42.

Voyer, D., \& Saunders, K. A. (2004). Gender differences on the mental rotations test: A factor analysis. Acta Psychologica, 117, 79-94.

Weinstein, S., \& Graves, R. E. (2001). Creativity, schizotypy, and laterality. Cognitive Neuropsychiatry, 6, 131-146.

Wohlschläger, A., \& Wohlschläger, A. (1998). Mental and manual rotation. Journal of Experimental Psychology: Human Perception and Performance, 24, 397-412.

Wraga, M., Shephard, J. M., Church, J. A., Inati, S., \& Kosslyn, S. M. (2005). Imagined rotations of self versus objects: An fMRI study. Neuropsychologia, 43, 1351-1361.

Zacks, J. M., Rypma, B., Gabrieli, J. D., Tversky, B., \& Glover, G. H. (1999). Imagined transformations of bodies: An fMRI investigation. Neuropsychologia, 37, 1029-1040.

Zacks, J. M., Vettel, J. M., \& Michelon, P. (2003). Imagined viewer and object rotations dissociated with event-related fMRI. Journal of Cognitive Neuroscience, 15, 1002-1018.

Received April 7, 2005

Revision received February 22, 2006

Accepted March 3, 2006 